\title{
ANALISIS PERHITUNGAN HARGA POKOK PRODUKSI DAN KELAYAKAN \\ USAHA SEDOTAN PRUPUK (Phragmites karka (Retz) Trin ex Steud) DI DESA TUMBANG NUSA, PULANG PISAU
}

\section{The Calculation of Cost of Production and Feasibility Study of Prupuk (Phragmites karka (Retz) Trin ex Steud) Straw Production in Tumbang Nusa Village, Pulang Pisau}

\author{
Arief R. Hakim ${ }^{1)}$, Asro L. Indrayanti ${ }^{2)}$, Febrianti ${ }^{3)}$ Novita Chandrawijaya ${ }^{4)}$ \\ 1,2 dan 4 Fakultas Pertanian Universitas PGRI Palangka Raya \\ ${ }^{3}$ CV. Cahaya Mas Kreasi Palangka Raya \\ email : gagukmartono@gmail.com; asroiin20@gmail.com \\ mailfebrianti@gmail.com dan novitachandrawijaya@yahoo.com
}

\begin{abstract}
ABSTRAK
Masyarakat Desa Tumbang Nusa Pulang Pisau mulai mengembangkan prupuk (Phragmites karka (Retz) Trin ex Steud) sebagai bahan sedotan untuk mengganti sedotan plastik yang sukar terurai. Penelitian ini bertujuan untuk menghitung harga pokok produksi, menyusun skenario harga jual serta melakukan analisis kelayakan usaha terhadap pengembangan sedotan dari bahan prupuk. Data primer dikumpulkan dari 20 orang pembuat sedotan prupuk dan dilengkapi dengan data sekunder dari berbagai erbitan terdahulu.

Hasil penelitian menunjukkan bahwa harga pokok produksi sedotan prupuk antara Rp. 374,3 - Rp. 408,68 per pcs. Proporsi pembiayaan sedotan prupuk adalah pembelian bahan baku $(59,72 \%$ - 65,14\%), upah pekerja $(34,36 \%$ - 39,58\%) dan biaya overhead $(0,6 \%-0,7 \%)$. Penentuan harga jual dilakukan dengan metode mark up dengan skenario I dengan tingkat keuntungan 10\% (sebesar Rp 389,04 untuk kemasan besar dan Rp. 449,54 untuk kemasan kecil) sampai skenario VI dengan tingkat keuntungan 60\% (sebesar Rp 565,88 untuk kemasan besar dan Rp. 653,88 untuk kemasan kecil). Harga sedotan pada skenario VI masih dapat bersaing dengan harga sedotan bambum sebagai competitor utamanya.

Meskipun harga mampu bersaing, namun tingkat produktivitas tenaga kerja sangat rendah. Pada kondisi Break Even Points telah tercapai, pendapatan tenaga kerja maksimal sebesar Rp. 180.062,74. Jika dibandingkan dengan UMR Kabupaten Pulang Pisau yang telah ditetapkan kontribusi pedapatan yang dari membuat sedotan purun hanya $6,11 \%$. Guna mencapai tingkat pendapatan setara UMR dibutuhkan omzet produksi sebesar 383 pcs per orang per hari atau setara dengan 7.652 pcs per orang per bulan. Dalam rangka meningkatkan kualitas dan kuantitas sedotan prupuk perlu dilakukan penerapan teknologi produksi.
\end{abstract}

Kata kunci : Prupuk (Phragmites karka (Retz) Trin ex Steud), sedotan, analisis ekonomi, harga pokok produksi, harga jual, kelayakan usaha

\section{ABSTRACT}

Communities in Tumbang Nusa Village, Jabiren Raya District Pulang Pisau Regency began to develop prupuk (Phragmites karka (Retz) Trin ex Steud) as a straw material to replace plastik that is difficult to decompose. This study aims to calculate the cost of production, 
develop a selling price scenario and conduct a feasibility study on the development of straws from prupuk. Primary data was collected from 20 people involved in making pru[uk straws and supplemented with secondary data from various previous studies and publications.

The results of this study indicate that the cost of production of prupuk straws ranges between IDR 374.3 - IDR 408.68 per pcs. The proportion of prupuk straw financing is for the purchase of raw materials (59.72\% to $65.14 \%)$, labor costs (34.36\% to $39.58 \%)$ and overhead costs for capital financing (0.6\% to $0.7 \%$ ). Determination of the selling price is done by adding the cost of goods manufactured to the desired profit (mark up method) with scenario I with a profit rate of 10\% (amounting to IDR 389.04 for large packages and IDR 449.54 for small packages) to scenario VI with a level of $60 \%$ profit (IDR 565.88 for large packages and IDR 653.88 for small packages). In terms of price, determining the selling price up to scenario VI can still compete with the prices of its competitors, namely bamboo straws.

Although the price of the product is competitive, the level of labor productivity is very low. At the break even point condition, the maximum labor income is only IDR 180,062.74. When compared with the UMR District of Pulang Pisau, the income contribution received from making this purun straw is very small (only 6.11\%). In order to achieve an income level equivalent to the UMR of Pulang Pisau Regency, a production turnover of 383 pcs per person per day is needed or equal to 7,652 pcs per person per month. In order to improve the quality and quantity of prupuk straws, it is necessary to apply production technology.

\section{Keywords : Prupuk (Phragmites karka (Retz) Trin ex Steud), straw, economic analysus, cost of production, selling price, feasibility study}

\section{PENDAHULUAN}

Pada saat ini, jumlah limbah plastik semakin meningkat, khususnya limbah yang berasal dari sedotan plastik. Penggunaan sedotan plastik sekali pakai di Indonesia termasuk yang tertinggi di dunia. Data yang dikumpulkan oleh Divers Clean Action memperkirakan pemakaian sedotan di Indonesia setiap harinya mencapai 93.244.847 batang. Sedotan itu berasal dari restoran, minuman kemasan, dan sumber lainnya (packed straw). Kemudian bila penggunaan sedotan ini dihitung dalam satu minggu, maka panjang keseluruhan sedotan ini adalah $117.449 \mathrm{~km}$, dan dapat menjadi "sabuk" bagi Bumi. Bahkan sabuk ini dapat tiga kali melilit mengitari Bumi. Jarak satu kali keliling Bumi adalah 40.075 km (Alicia, 2018).

Kemudahan dalam mendapatkan sedotan plastik sekali pakai dinilai menjadi penyebab banyaknya sedotan plastik mengotori bumi. Menurut peneliti asal Australia, Wilcox, Denise dan Hardesty (2015) dalam Idrus dkk., (2019), terdapat lebih dari 8 milyar sedotan bekas yang ditemukan di sepanjang bibir pantai dunia setiap tahunnya. Tak hanya sulit diurai dan didaur ulang, sampah plastik ternyata juga sangat berbahaya bagi kelangsungan hidup biota laut. Bentuknya yang kecil seringkali 
tersangkut, bahkan termakan oleh penyu, ikan, dan burung yang dapat menyebabkan keracunan pada hewan. Pada akhirnya manusia pun akan terkena dampaknya karena manusia juga merupakan bagian dari mata rantai siklus makanan.

Beberapa penelitian telah dilakukan untuk mencari bahan pengganti plastic dengan bahan yang mudah terdegradasi diantaranya mengembangkan pengganti plastic yang berasal dari bahan pati ubi jalar (Aripin, 2017) dari bahan baku pati sagu dan ubi kayu (Kamsiati, 2017) serta bonggol pisang kepok dan cangkang bekicot (Nafiyanto, 2019). Di samping itu juga ada upaya untuk memanfaatkan limbah plastic menjadi produk kreatif (Arico dan Sri Jayanthi, 2017) atau dibentuk dalam hasil kriya (seni rupa) berupa patung binatang dan lifestyle board dengan teknik hot textile (Chintya, 2017) atau dengan konsep daur ulang (Handayani dkk., 2009) serta menggunakan alat pencacah untuk meningkatkan nilai jualnya (Suartika dkk., 2015). Pemerintah juga telah berupaya untuk mengenakan cukai terhadap bahan baku plastic dan tas plastic namun hasilnya belum sepenuhnya memuaskan (Suryani, 2016; Saraswaty, 2018).

Dalam hal penggunaan sedotan, telah mulai dikembangkan sedotan dengan bahan baku selain plastic baik yang untuk pemakaian satu kali maupun sedotan pakai ulang diantaranya sedotan dari pati jagung, sedotan kaca, sedotan buluh bambu, sedotan stainless steel, sedotan akrilik, sedotan kertas dan sedotan silicon (Alicia, 2018; Mustinda, 2019) serta rumput laut (Anggraini, 2017). Indonesia memiliki bahan sedotan yang berasal dari tumbuhan seperti purun danau (Lepironia articulata (Retz) Domin) dan jerami padi (Oryza sativa $\mathrm{L}$.$) .$

Salah satu spesies tumbuhan yang mempunyai potensi untuk digunakan sebagai bahan sedotan adalah prupuk (Phragmites karka (Retz) Trin ex Steud). Prupuk merupakan tumbuhan rumput besar dan menahun dari Kelas Poaceae yang biasa tumbuh di tepi sungai/rawa, tanahtanah becek dan lembat termasuk tanah gambut. Prupuk tersebar di seluruh wilayah Indonesia sehingga mempunyai nama daerah yang bermacam-macam, yaitu palungpung, bayongbong, gayonggong, kasongket (Sd), prumpung, perumpung, plumpung, glagah asu (Jw), parongpong (Md), parumpung, parungpung (B1), atowong, gumulongo (Minh). Tatepal, tatupele, tиуu, kasim, biet, ceo-ceo, lolo dowongi (aneka bahasa di Maluku). Dalam klasifikasi tumbuhan, perupuk termasuk dalam tumbuhan 
monokotil. Selama ini batang prupuk (sebenarnya adalah tangkai bunga prupuk) dimanfaatkan sebagai alat memancing (ganggang, doran, walesan).

Masyarakat di Desa Tumbang Nusa Kecamatan Jabiren Raya Kabupaten Pulang Pisau mulai mengembangkan prupuk sebagai bahan sedotan untuk mengganti sedotan plastik yang sukar terurai. Prupuk tumbuh secara liar di sepanjang Sungai Kahayan Kalimantan Tengah dan mudah berkembang di lahan gambut, sehingga dapat dijadikan salah satu komoditi alternatif dalam restorasi lahan gambut di Provinsi Kalimantan Tengah. Pembuatan sedotan prupuk ini dilakukan oleh 20 orang ibu rumah tangga dan masih dikembangkan dalam skala kecil dengan menggunakan teknologi serta peralatan yang sederhana. Penelitian ini bertujuan untuk menghitung harga pokok produksi, menyusun skenario harga jual serta melakukan analisis kelayakan usaha terhadap pengembangan sedotan dari bahan perupuk. Hasil penelitian ini akan membantu produsen sedotan prupuk untuk menentukan harga jual produknya serta menentukan kelayakan usaha (feasibily study) dalam produksi sedotan prupuk di Desa Tumbang Nusa Kecamatan Jabiren Raya Kabupaten Pulang Pisau.

\section{METODE PENELITIAN}

Metode dasar yang digunakan dalam penelitian ini adalah metode deskriptif . Metode deskriptif adalah suatu metode dalam meneliti status sekelompok manusia, suatu objek, suatu set kondisi, suatu sistem pemikiran ataupun suatu klas peristiwa. Tujuan dari penelitian deskriptif adalah untuk membuat deskripsi, gambaran, lukisan secara sistematis, faktual dan akurat mengenai fakta-fakta, sifat-sifat serta hubungan antara berbagai fenomena yang diteliti (Nazir, 2000). Dengan kata lain, Peneliti melakukan observasi kemudian menggambarkan atau mendiskripsikan hasil pengamatannya. Karena observasi ilmiah dilakukan lebih hati-hati dan lebih terstruktur maka hasilnya lebih baik dibandingkan observasi yang dilakukan orang awam (Babbie, 1995). Penelitian deskriptif dimaksudkan untuk pengukuran yang cermat terhadap fenomena sosial tertentu. Peneliti mengembangkan konsep dan menghimpun fakta tetapi tidak melakukan pengujian hipotesa (Singarimbun, 1989).

Penelitian dilakukan di Desa Tumbang Nusa Kecamatan Jabiren Raya Kabupaten Plang Pisau, karena produksi sedotan prupuk baru dimulai di desa ini. Sampel penelitian diambil dari anggota BUMDes Harapan Kita yang berjumlah 
20 orang. BUMDes Harapan Kita dipilih karena merupakan satu-satunya kelompok masyarakat yang mulai memproduksi sedotan prupuk. Penelitian dilakukan selama 2 bulan sejak bulan November sampai Bulan Desember 2019.

Penelitian ini menggunakan data primer yang diperoleh melalui wawancara dengan para respnden serta data sekunder yang berasal dari literatur/jurnal/penerbitan/pustaka yang berkaitan dengan topik penelitian. Ada 3 hal yang akan dihitung dalam penelitian ini, yaitu :

\section{Harga Pokok Produksi}

Dalam perhitungan harga pokok penjualan di industri terdapat beberapa unsur yang harus diperhatikan, diantaranya adalah elemen-elemen pembentuk harga pokok produksi yaitu biaya bahan baku, biaya tenaga kerja langsung dan biaya overhead pabrik. Menurut Lambajang (2013) dalam Widyastuti dan Mita (2018) Harga Pokok Produksi merupakan kumpulan dari biaya-biaya yang dikeluarkan untuk mengolah bahan baku menjadi barang jadi, sehingga dapat disimpulkan bahwa penentuan harga pokok produksi dihitung dengan menggabungkan seluruh elemen biaya produksi baik tetap maupun variabel
(Hartoyo, 2016 dalam Widyastuti dan Mita, 2018).

Dalam penelitian ini Harga Pokok Produksi (HPP) dihitung dengan menjumlahkan biaya yang dikeluarkan untuk pembelian bahan (BB), biaya upah tenaga kerja (UTK) dan biaya overhead (BOH) yang dirumuskan sebagai berikut :

$\mathrm{HPP}=\mathrm{BB}+\mathrm{UTK}+\mathrm{BOH}$

Biaya pembelian bahan (BB) meliputi biaya yang digunakan untuk membeli bahan yang dipergunakan untuk satu proses produksi, baik bahan pokok maupun bahan penolong. Alat yang hanya dipergunakan untuk satu kali produksi diklasifikasikan sebagai bahan. Upah tenaga kerja (UTK) adalah pengorbanan yang dikeluarkan untuk membayar penggunaan tenaga kerja untuk mengolah bahan baku menjadi produk. Sementara biaya overhead $(\mathrm{BOH})$ dihitung dari biaya penggunaan asset tetap selama proses produksi. Biaya penggunaan asset tetap ini dihitung sebagai biaya overhead karena asset-asset tersebut (pada saat ini) tidak hanya digunakan untuk produksi sedotan prupuk tetapi juga untuk proses produksi yamg lain.

2. Harga Jual 
Kotler dan Keller (2009) menyatakan bahwa, harga jual adalah sejumlah uang yang dibebankan atas suatu produk atau jasa, atau jumlah dari nilai yang ditukar konsumen atas manfaatmanfaat karena memiliki atau menggunakan produk atau jasa tersebut (cit. Pelealu dkk. 2018). Penentuan harga jual ini diperlukan untuk mengetahui posisi sedotan prupuk dibandingkan dengan pesaingnya yang sudah ada di pasar. Pada prinsipnya harga jual harus dapat menutupi biaya penuh ditambah dengan laba yang wajar. Dalam penelitian ini Harga jual sama dengan harga pokok produksi ditambah dengan keuntungan (mark up).

3. Analisis kelayakan usaha

Layak tidaknya suatu usaha yang akan dilaksanakan dapat dilihat dari analisis kelayakannya. Beberapa parameter yang dapat dipergunakan untuk melihat kelayakan suatu usaha umumnya adalah analisis rasio $\mathrm{B} / \mathrm{C}$, payback period (PBP), dan analisis titik impas BEP produksi (pcs) $\quad=\frac{\text { Total Biaya }}{\text { Harga Jual }}$ PTK $=\%$ UTK $\times$ HPP $\times$ BEP produksi

Berdasarkan perhitungan dari persamaan (3) akan diketahui apakah atau break even point (BEP), selain itu, akan lebih baik jika dilengkapi dengan perhitungan produktivitas tenaga kerja (PTK) (Lestari dkk., 2015; Prasetya dkk., 2017). Dalam penelitian ini analisis kelayakan dihitung dengan Break Event Point (BEP) produksi dan produktivitas tenaga kerja (PTK). BEP Produksi menyatakan jumlah unit minimal yang harus diproduksi agar tercapai titik impas investasi, sedangkan produktivitas tenaga kerja menyatakan jumlah pendapatan yang diperoleh tenaga kerja yang bekerja di industri pembuatan sedotan prupuk pada saat terjadi BEP produksi (Yuwani dkk., Prasetya dkk., 2017). Indikator tersebut dipilih karena sedotan prupuk sendiri belum diproduksi secara masal dan masih dalam tahap uji coba produk serta merupakan

diversifikasi/pengembangan produk dari produk lain yang dikerjakan oleh kelompok usaha yang sama. Nilai masing-masing BEP diperoleh dengan formula berikut (Prasetya dkk., 2017)

produktivitas tenaga kerja (PTK) mampu memenuhi standar Upah 
Minimum Regional (UMR) UMR (Volume Produksi UMR) dapat Kalimanatan Tengah tahun 2020. terpenuhi dengan formula sebagai Analisis lebih lanjut dapat diketahui berikut :

volume produksi minimal sehingga

Volume produksi UMR (pcs) $=\frac{\text { UMR Pulang Pisau } 2020}{\% \text { UTK } \times \text { HPP }}$

\section{HASIL PENELITIAN}

1. Harga Pokok Produksi

Berdasarkan hasil wawancara dengan responden diketahui bahwa sedotan yang diproduksi di kemas dalam 2 kemasan yaitu kemasan kecil (berisi 50 pcs) dan kemasan besar (berisi 100 pcs). Hasil perhitungan biaya pokok produksi untuk setiap kemasan disajikan dalam tabel berikut.

Tabel 1. Perhitungan Biaya Pokok Produksi Sedotan Prupuk Desa Tumbang Nusa

\begin{tabular}{|c|c|c|c|c|c|}
\hline \multirow{2}{*}{ NO } & \multirow{2}{*}{ URAIAN } & \multicolumn{4}{|c|}{ BIAYA PER PCS } \\
\hline & & \multicolumn{2}{|c|}{ Kemasan Kecil } & \multicolumn{2}{|c|}{ Kemasan Besar } \\
\hline A. & BAHAN & & & & \\
\hline 1 & Batang Prupuk & Rp. & 40.00 & Rp. & 40.00 \\
\hline 2 & Serai wangi & Rp. & 40.00 & $\mathrm{Rp}$. & 40.00 \\
\hline 3 & Desinfektan & Rp. & 0.21 & $\mathrm{Rp}$. & 0.21 \\
\hline 4 & Amplas & Rp. & 16.00 & Rp. & 16.00 \\
\hline 5 & Pisau cuter & Rp. & 10.00 & Rp. & 10.00 \\
\hline 6 & gas dan air & Rp. & 50.00 & $\mathrm{Rp}$. & 50.00 \\
\hline 7 & Kemasan & Rp. & 100.00 & $\mathrm{Rp}$. & 50.00 \\
\hline 8 & Stiker & Rp. & 10.00 & Rp. & 5.00 \\
\hline \multicolumn{2}{|c|}{ JUMLAH BIAYA BAHAN } & Rp. & 266.21 & Rp. & 211.21 \\
\hline B. & UPAH TENAGA KERJA & & & & \\
\hline 1 & Upah potong dan amplas & Rp. & 100.00 & Rp. & 100.00 \\
\hline 2 & Upah jemur dan perebusan & Rp. & 40.00 & Rp. & 40.00 \\
\hline \multicolumn{2}{|c|}{ JUMLAH UPAH } & Rp. & 140.00 & Rp. & 140.00 \\
\hline \multicolumn{6}{|c|}{ C. OVERHEAD } \\
\hline 1 & Panci & Rp. & 0.80 & Rp. & 0.80 \\
\hline 2 & Kompor & Rp. & 1.67 & Rp. & 1.67 \\
\hline \multicolumn{2}{|c|}{ JUMLAH BIAYA OVERHEAD } & Rp. & 2.47 & Rp. & 2.47 \\
\hline \multicolumn{2}{|c|}{ JUMLAH BIAYA PER PCS } & Rp. & 408.68 & $\mathrm{Rp}$. & 352.68 \\
\hline
\end{tabular}

Sumber : Analisis Data Primer 
Berdasarkan data Tabel 1 tersebut perbedaan harga satuan (harga per pcs) untuk sedotan kemasan kecil da kemasan besar terpaut sebesar Rp. 55,yang disebabkan perbedaan harga kemasan, sementara komponen harga yang lain sama. Proporsi biaya dari setiap komponen dapat dilihat pada tabel berikut.

Tabel 2. Proporsi Komponen Biaya Produksi Sedotan Prupuk di Desa Tumbang Nusa

\begin{tabular}{rlrrrrrr}
\hline \multirow{2}{*}{ No } & \multirow{2}{*}{ Komponen Biaya } & \multicolumn{3}{c}{ Kemasan Kecil } & \multicolumn{3}{c}{ Kemasan Besar } \\
\cline { 3 - 8 } & & \multicolumn{2}{c}{ Nominal } & \multicolumn{1}{c}{$\%$} & \multicolumn{2}{c}{ Nominal } & \multicolumn{1}{c}{$\%$} \\
\hline 1 & Biaya Bahan Baku & Rp. & 266.21 & 65.14 & Rp. & 211.21 & 59.72 \\
2 & Biaya Upah Tenaga Kerja & Rp. & 140.00 & 34.26 & Rp. & 140.00 & 39.58 \\
3 & Biaya Overhead & Rp. & 2.47 & 0.60 & Rp. & 2.47 & 0.70 \\
\hline & JUMLAH & Rp. & 408.68 & 100.00 & Rp. & 353.68 & 100.00 \\
\hline
\end{tabular}

Sumber : Analisis Data Primer

Berdasarkan tabel di atas terlihat bahwa proporsi terbesar dari struktur biaya produksi sedotan prupuk adalah untuk pembelian bahan baku $(59,72 \%$ - 65,14\%), diikuti dengan komponen biaya upah tenaga kerja $(34,26 \%$ $39,58 \%$ ) dan terakhir komponen biaya overhead $(0,60 \% \quad-0,70 \%)$. Berdasarkan pengamatan di lapangan, pembuatan sedotan prupuk di Desa Tumbang Nusa masih menggunakan teknologi dan peralatan yang sederhana, hal ini juga terlihat dari struktur biaya pembuatan sedotan prupuk seperti terlihat pada Tabel 1 dan Tabel 2.

2. Harga Jual

Pada saat penelitian dilakukan, para pembuat sedotan prupuk masih melakukan pengenalan produk di beberapa tempat, namun penjualan resmi belum dilakukan. Berkenaan dengan hal ini, penentuan harga jual dilakukan dengan metode mark up yaitu menentukan harga jual dengan menambah keuntungan/laba pada harga pokok produksi. Hasil perhitungan harga jual dengan 6 skenario $(10 \%, 20$ $\%, 30 \%, 40 \%, 50 \%$ dan $60 \%$ ) disajikan pada tabel di bawah ini.

Tabel 3. Skenario Harga Jual Sedotan Prupuk di Desa Tumbang Nusa

\begin{tabular}{clllll}
\hline \multirow{2}{*}{ No } & \multicolumn{2}{c}{ Skenario } & \multicolumn{4}{c}{ Kemasan Per Pcs } \\
\cline { 3 - 6 } & & \multicolumn{3}{c}{ Kemasan Kecil } & \multicolumn{2}{c}{ Kemasan Besar } \\
\hline 1 & Harga Pokok Produksi & $\mathrm{Rp}$ & 408.68 & $\mathrm{Rp}$ & 353.68 \\
2 & Skenario I (Mark up 10 \%) & $\mathrm{Rp}$ & 449.54 & $\mathrm{Rp}$ & 389.04
\end{tabular}




\begin{tabular}{llllll}
3 & Skenario II (Mark up 20 \%) & $\mathrm{Rp}$ & 490.41 & $\mathrm{Rp}$ & 424.41 \\
4 & Skenario III (Mark up 30 \%) & $\mathrm{Rp}$ & 531.28 & $\mathrm{Rp}$ & 459.78 \\
5 & Skenario IV (Mark up 40 \%) & $\mathrm{Rp}$ & 572.15 & $\mathrm{Rp}$ & 495.15 \\
6 & Skenario V (Mark up 50 \%) & $\mathrm{Rp}$ & 613.01 & $\mathrm{Rp}$ & 530.51 \\
7 & Skenario VI (Mark up 60 \%) & $\mathrm{Rp}$ & 653.88 & $\mathrm{Rp}$ & 565.88 \\
\hline
\end{tabular}

Sumber : Analisis Data Primer

Berdasarkan hasil skenario harga jual tersebut, harga jual sedotan prupuk dalam kemasan kecil berkisar antara Rp. 449,54 - Rp. Rp. 653,88 per pcs sementara untuk kemasan besar berkisar dari Rp. 389,04 - Rp. 565,88 per pes. Harga jual yang dapat dipilih oleh produsen sedotan prupuk ditentukan oleh beberapa faktor diantaranya adalah harga barang competitor serta tingkat pendapatan yang diinginkan.

\section{Analisis Kelayakan Usaha}

Analisis kelayakan usaha dilakukan dengan menghitung Break Event Point (BEP) produksi dan produktivitas tenaga kerja (PTK). Berdasarkan data perhitungan biaya pokok produksi (tabel 1), hanya ada 2 jenis biaya tetap (fix cost) yang digunakan selama proses produksi yaitu biaya pembelian panci (sebesar Rp. 150.000,-) dan biaya pembelian kompos gas (sebesar Rp. 350.000,-). Hasil perhitungan BEP Produksi industri sedotan prupuk di Desa Tumbang Nusa disajikan pada tabel berikut.

Tabel 4. BEP Produksi dan PTK Pembuatan Sedotan Prupuk di Desa Tumbang Nusa

\begin{tabular}{|c|c|c|c|c|c|c|c|}
\hline \multirow{2}{*}{ No } & \multirow{2}{*}{ Indikator Kelayakan } & \multicolumn{6}{|c|}{ Nilai nominal (dalam Rupiah) } \\
\hline & & Skenario I & Skenario II & Skenario III & Skenario IV & Skenario V & Skenario VI \\
\hline \multirow[t]{3}{*}{1} & Total Biaya Produksi & & & & & & \\
\hline & a. Kemasan Kecil & $500,406.21$ & $500,406.21$ & $500,406.21$ & $500,406.21$ & $500,406.21$ & $500,406.21$ \\
\hline & b. Kemasan Besar & $500,371.83$ & $500,371.83$ & $500,371.83$ & $500,371.83$ & $500,371.83$ & $500,371.83$ \\
\hline \multirow[t]{3}{*}{2} & Harga Jual & & & & & & \\
\hline & a. Kemasan Kecil & 449.54 & 490.41 & 531.28 & 572.15 & 613.01 & 653.88 \\
\hline & b. Kemasan Besar & 389.04 & 424.41 & 459.78 & 495.15 & 530.51 & 565.88 \\
\hline \multirow[t]{3}{*}{3} & BEP Produksi (pcs) & & & & & & \\
\hline & a. Kemasan Kecil & $1,113.15$ & $1,020.38$ & 941.89 & 874.61 & 816.31 & 765.29 \\
\hline & b. Kemasan Besar & $1,286.16$ & $1,178.98$ & $1,088.29$ & $1,010.56$ & 943.19 & 884.24 \\
\hline \multirow[t]{3}{*}{4} & Produktivitas Tenaga Kerja & & & & & & \\
\hline & a. Kemasan Kecil & $155,840.37$ & $142,853.67$ & $131,864.93$ & $122,446.00$ & $114,282.94$ & $107,140.25$ \\
\hline & b. Kemasan Besar & $180,062.74$ & $165,057.51$ & $152,360.78$ & $141,477.86$ & $132,046.01$ & $123,793.13$ \\
\hline
\end{tabular}


5 Prediksi Keuntungan pada BEP Produksi

\begin{tabular}{|c|c|c|c|c|c|c|}
\hline a. Kemasan Kecil & $45,491.47$ & $83,401.03$ & $115,478.36$ & $142,973.20$ & $166,802.07$ & $187,652.3$ \\
\hline b. Kemasan Besar & $18,961.25$ & $59,078.80$ & $93,024.42$ & $122,120.66$ & $147,337.40$ & 169,402 \\
\hline \multicolumn{7}{|c|}{ Laba ditambah PTK pada BEP Produksi } \\
\hline a. Kemasan Kecil & $201,331.84$ & $226,254.71$ & $247,343.28$ & $265,419.21$ & $281,085.01$ & 294,792 \\
\hline b. Kemasan Besar & $199,023.98$ & $224,136.31$ & $245,385.19$ & $263,598.52$ & $279,383.41$ & 293,195 \\
\hline
\end{tabular}

Sumber : Analisis Data Primer

Tabel di atas menunjukkan bahwa pendapatan tenaga kerja tertinggi sebesar Rp. 180.062,74 dan jika keuntungan usaha digabungkan maka jumlah pendapatan pada keadaan BEP produksi tercapai maksimal sebesar Rp. 294.792,58

Pemerintah Provinsi Kalimantan Tengah melalui Peraturan Gubernur Kalimantan Tengah Nomor 34 Tahun 2019 telah menetapkan Upah Minimum Kabupaten Pulang Pisau sebesar Rp. 2.947.368,-. Jika nilai UMR tersebut dibandingkan dengan

Volume produksi UMR (pcs) $\quad=\frac{2.947 .368}{140}$ $=21.052,63$ atau dibulatkan menjadi $21.053 \mathrm{pcs}$ produktivitas tenaga kerja (Tabel 4 angka 4), maka upah tenaga kerja yang bekerja dalam pembuatan sedotan prupuk ini masih jauh dari UMR. Bahkan seandainya pekerja tersebut adalah pemilik usaha, maka keuntungannya sebagai pengusaha digabung dengan upahnya sebagai pekerja (Tabel 4 angka 6) masih berada dibawah UMR. Untk mengetahui volume produksi minimal untuk mencapai UMR maka nilai UMR ini disubstitusikan dalam persamaan (4) sebagai berikut
Dengan demikian, agar nilai UMR Kabupaten Pulang Pisau dapat tercapai, maka seorang pekerja/pembuat sedotan prupuk harus mampu menghasilkan minimal 21,053 pcs per bulan. Jika pekerja tersebut sekaligus adalah pemilik usaha, maka gabungan keuntungan dan produktivitas disajikan pada tabel berikut ini.

Tabel 5. Volume Produksi Minimal untuk mencapai UMR untuk Pekerja sekaligus Pemilik 
Usaha pembuatan Sedotan Prupuk

\begin{tabular}{|c|c|c|c|c|c|c|c|}
\hline \multirow[b]{2}{*}{ No } & \multirow[b]{2}{*}{ Indikator Kelayakan } & \multicolumn{6}{|c|}{ Nilai nominal } \\
\hline & & $\begin{array}{c}\text { Skenario } \\
\text { I }\end{array}$ & $\begin{array}{c}\text { Skenario } \\
\text { II }\end{array}$ & $\begin{array}{c}\text { Skenario } \\
\text { III }\end{array}$ & $\begin{array}{c}\text { Skenario } \\
\text { IV }\end{array}$ & $\begin{array}{c}\text { Skenario } \\
\mathrm{V}\end{array}$ & $\begin{array}{c}\text { Skenario } \\
\text { VI }\end{array}$ \\
\hline \multirow[t]{3}{*}{1} & \multicolumn{7}{|c|}{ Upah Tenaga Kerja (Rp/pcs) } \\
\hline & a. Kemasan Kecil & 140.00 & 140.00 & 140.00 & 140.00 & 140.00 & 140.00 \\
\hline & b. Kemasan Besar & 140.00 & 140.00 & 140.00 & 140.00 & 140.00 & 140.00 \\
\hline \multirow[t]{3}{*}{2} & \multicolumn{7}{|c|}{ Keuntungan Penjualan (Rp / pcs ) } \\
\hline & a. Kemasan Kecil & 40.87 & 81.74 & 122.60 & 163.47 & 204.34 & 245.21 \\
\hline & b. Kemasan Besar & 14.74 & 50.11 & 85.48 & 120.85 & 156.21 & 191.58 \\
\hline \multirow[t]{3}{*}{3} & \multicolumn{7}{|c|}{ Volume Produksi Minimal untuk mencapai UMR (pcs) } \\
\hline & a. Kemasan Kecil & $16,295.73$ & $13,292.30$ & $11,223.69$ & $9,712.22$ & $8,559.53$ & $7,651.43$ \\
\hline & b. Kemasan Besar & $19,046.92$ & $15,503.49$ & $13,071.67$ & $11,299.31$ & $9,950.18$ & $8,888.86$ \\
\hline
\end{tabular}

Sumber : Analisis Data Primer

Berdasarkan data volume produksi minimum yang ditampilkan pada tabel di atas terlihat bahwa untuk mencapai tingkat pendapatan sebesar UMR Kabupaten Pulang Pisau diperlukan produksi sedotan minimal sebanyak 7.651,43 (dibuatkan menjadi 7.652) pes per bulan yang dijual dengan harga Rp. 653,88 per pcs. Jika seorang pekerja bekerja selama 20 hari per bulan, maka secara rata-rata dia harus menghasilkan sedotan minimal 383 pcs per hari.

\section{PEMBAHASAN}

Hasil penelitian ini menunjukkan bahwa proses produksi sedotan prupuk masih menggunakan sederhana, yang dapat dilihat dari proporsi bahan baku dan tenaga kerja sangat dominan dalam proses produksi (lebih dari $99 \%$ dari struktur biaya produksi). Sementara proporsi teknologi sangat kecil (kurang dari $1 \%$ ). Proporsi teknologi yang sangat kecil ini disebabkan keterbatasan modal yang dimiliki para pembuat sedotan prupuk. Kondisi ini sesuai dengan keadaan UMKM di beberapa daerah di Indonesia yang pernah diteliti misalnya di bidang border dan konveksi (Sanusi, 2015), di bidang kuliner/jajanan (Prasatya dkk., 2017) serta berbagai jenis usaha (Suci, 2017). Ciri-ciri umum UMKM yang demikian diantaranya rasio manfaat biaya (B/C ratio) secara ekonomi layak, titik impas (Break Even Points) dan Payback Periods (PBP) tercapai dengan cepat namun produktivitas tenaga kerja nya rendah (Prasetya dkk., 2017). Pada kondisi titik impas (Break Even Points) telah tercapai, pendapatan 
tenaga kerja maksimal hanya sebesar Rp. 180.062,74, dan jika dibandingkan dengan UMR Kabupaten Pulang Pisau yang telah ditetapkan sebesar 2.947.368,- maka kontribusi pedapatan yang diterima dari membuat sedotan purun ini sangat kecil (hanya 6,11\%).

Dengan produktivitas tenaga kerja yang rendah, maka proses pembuatan sedotan prupuk ini rawan ditinggalkan oleh pelakunya. Kondisi ini juga terjadi di sektor pertanian sebagaimana hasil penelitian Prawesti dkk. (2010) dan Anshauri dkk., (2017) yang menemukan bahwa motivasi anak petani untuk menjadi petani sangat rendah (kurang dari $30 \%$ ). Meskipun memiliki daya saing yang rendah, UMKM dengan tipologi seperti ini mempunyai daya tahan yang tinggi karena $\mathrm{B} / \mathrm{C}$ ratio yang tinggi serta titik impas (Break Even Points) dan Payback Periods (PBP) tercapai dengan cepat. Ketika harga bahan baku naik atau harga jual turun, berbagai parameter tersebut tetap menunjukkan nilai yang layak (Prasetyo dkk., 2017).

Dari sisi harga jual, dengan skenario mark up sampai dengan $60 \%$ dari harga pokok produksi masih bisa bersaing. Kompetitor utama dari sedotan prupuk adalah sedotan bambu. Harga jual sedotan bambu yang ada di pasar sebesar Rp.
2.000,- per pcs dengan minimal pembelian sebanyak 100 pes (Hamdani, 2019). Keunggulan sedotan bambu dibanding sedotan prupuk adalah daya tahannya. Dengan perawatan yang baik, sedotan bambu bisa bertahan selama 2 tahun tanpa rusak atau berjamur. Dibandingkan dengan sedotan bambu, daya tahan sedotan prupuk relatif lebih rendah dan memerlukan wadah khusus supaya tidak pecah, namun dengan harga yang lebih murah sedotan prupuk akan cocok dengan konsumen yang penggunaannya sekali pakai.

Kebutuhan untuk menerapkan teknologi sangat tinggi untuk meningkatkan produktivitas para pembuat sedotan prupuk, apalagi untuk mencapai tingkat pendapatan setara dengan UMR Kabupaten Pulang Pisau dibutuhkan omzet produksi sebesar 383 pcs per orang per hari atau setara dengan 7.652 pcs per orang per bulan. Penggunaan teknologi mampu meningkatkan kualitas dan kuantitas pengrajin sedotan bambu di Kecamatan Praya Barat (Idrus dkk., 2019). Pengunaan teknologi juga bermanfaat untuk menciptakan branding, dan peningkatan branding ini akan berdamapak pada penjualan (Sanusi, 2015; Prasatya dkk., 2017). 


\section{KESIMPULAN}

Hasil penelitian ini menunjukkan bahwa harga pokok produksi sedotan prupuk berkisar antara Rp. 374,3 - Rp. 408,68 per pcs. Proporsi pembiayaan sedotan prupuk adalah untuk pembelian bahan baku $(59,72 \%$ sampai $65,14 \%)$, upah tenaga kerja $(34,36 \%$ sampai 39,58 $\%$ ) dan biaya overhead untuk pembiayaan modal $(0,6 \%$ sampai $0,7 \%)$. Penentuan harga jual dilakukan dengan menambah harga pokok produksi dengan laba yang diinginkan (metode mark up) dengan skenario I dengan tingkat keuntungan $10 \%$ (sebesar Rp 389,04 untuk kemasan besar dan Rp. 449,54 untuk kemasan kecil) sampai skenario VI dengan tingkat keuntungan $60 \%$ (sebesar Rp 565,88 untuk kemasan besar dan Rp. 653,88 untuk kemasan kecil). Dari segi harga, penentuan harga jual sampai dengan skenario VI (tingkat keuntungan $60 \%$ ) masih dapat bersaing dengan harga kompetitornya, yaitu sedotan bambu.

Meskipun harga produk mampu bersaing, namun tingkat produktivitas tenaga kerja sangat rendah. Pada kondisi titik impas (Break Even Points) telah tercapai, pendapatan tenaga kerja maksimal hanya sebesar Rp. 180.062,74. Jika dibandingkan dengan UMR Kabupaten Pulang Pisau yang telah ditetapkan sebesar 2.947.368,- maka kontribusi pedapatan yang diterima dari membuat sedotan purun ini sangat kecil (hanya 6,11\%). Guna mencapai tingkat pendapatan setara dengan UMR Kabupaten Pulang Pisau dibutuhkan omzet produksi sebesar 383 pcs per orang per hari atau setara dengan 7.652 pcs per orang per bulan. Dalam rangka meningkatkan kualitas dan kuantitas sedotan prupuk perlu dilakukan penerapan teknologi produksi.

\section{UCAPAN TERIMA KASIH}

Tim Peneliti mengucapkan terima kasih kepada Jajaran Pemerintah Desa Tumbang Nusa serta seluruh Pengurus dan Anggota BUMDes Harapan Kita Desa Tumbang Nusa yang telah membantu kami dalam penyelesaian penelitian ini.

\section{REFERENSI}

Alicia, N. 2018. Sampah Sedotan Plastik Mengancam Bumi, Berbagai Pihak Mulai Berbenah. https://nationalgeographic.grid.id/am p/13941728/sampah-sedotan-plastikmengancam-bumi-berbagai-pihakmulai-berbenah?page=all. (diakses tanggal 17 Januari 2020).

Anggraini, D. 2017 Nyam! Tak Usah Dibuang Sedotan Ini Bisa Langsung Dimakan https://food.detik.com/infokuliner/d-3771639/nyam-tak-usahdibuang-sedotan-ini-bisa-langsungdimakan (diakses tanggal 17 Januari 2020). 
Anshauri, S., A.L. Indrayanti dan A.R. Hakim. 2017. "Persepsi Pemuda terhadap Pertanian di Desa Anjir Muara Lama Kecamatan Anjir Muara Kabupaten Barito Kuala" Prosiding Seminar Kohimdo III. Palangka Raya. 3 Nopember 2017.

Arico, Z dan Sri Jayanthi. 2017. "Pengolahan Limbah Plastik menjadi Produk Kreatif sebagai Peningkatan Ekonomi Masyarakat Pesisir." Martable : Jurnal Pengabdian Masyarakat 1(1):1-6

Aripin, S., B. Saing dan E. Kustiyah. 2017. "Studi Pembuatan Bahan Alternatif Plastik Biodegradable dari Pati Ubi Jalar dengan Plasticizer Gliserol dengan Metode Melt Intercalation" Jurnal Teknik Mesin (JTM) 06 (Edisi Spesial) : $18-23$.

Babbie, Earl. 1995. The Practice of Social Research. Seventh Edition. Wadsword Publishing Company. Belmont. California.

Chintya, V. 2017. "Eksploitasi Material Limbah Sedotan Plastik" $e$ Proceeding of Art \& Design 4 (3) : 1067 - 1086

Hamdani, T. 2019. Sedotan Bambu Ramah Lingkungan yang 'Terbang' hingga ke Australia https://m.detik.com/finance/solusiuk m/d-4491722/sedotan-bambu-ramahlingkungan-yang-terbang-hingga-keaustralia (diakses Tanggal 17 Januari 2020)

Handayani, D.W., S.H. Budisulistiorini dan M.R. Nuraini. 2009. "Kajian Nilai Ekonomi Penerapan Konsep Daur Ulang pada TPA Jatibarang Kota Semarang" Jurnal Presipitasi 7 (2) : $35-44$.

Idrus, S, I.P. Gede dan I.K. Purawata. 2019. "Pemberdayaan Kelompok Natural Bamboo Straw Lombok Dusun Emboan Desa Mangkung Kecamatan Praya Barat". Jurnal Biwakarya 14 (2) : 2055-2060 http://ejurnal.binawakya.or.id/index. php/MBI

Kamsiati, E., H. Herawati dan E.Y. Purwani. 2017. "Potensi Pengembangan Plastik Biodegradable Berbasis Pati Sagu dan Ubikayu di Indonesia". Jurnal Litbang Pertanian 36 (2) : 67 - 76

Lestari, R.D., L.M. Baga dan R. Nurmalina. $2015 . \quad$ "Analisis Keuntungan Finansial Usaha Penggemukan Sapi Potong di Kabupaten Bojonegoro" SEPA 11 (2): $207-215$

Mustinda, L. 2019. Bukan Plastik! Wajib Punya 5 Sedotan yang Ramah Lingkungan https://food.detik.com/info-kuliner/d4509822/bukan-plastik-wajib-punya5-sedotan-yang-ramah-lingkungan (diakses tanggal 18 Januari 2020)

Nafiyanto, I. 2019. "Pembuatan Plastik Biodegradable dari Limbah Bonggol Pisang Kepok dengan Plastilizer Gliserol dari Minyak Jelantah dan Komposit Kitosan dari Limbah Cangkang Bekicot (Achatina fullica)" Integrated Lab Journal | 07 (01) : $75-89$

Nazir, Muhammad. 2003. Metode Penelitian. Ghalia Indonesia. Jakarta.

Prasatya, F.A., T. Muhandri, dan E.R. Cahyadi. 2017. "Faktor Keberhasilan Usaha UMKM Jajanan Asing Kaki Lima di Kota Serang" Manajemen IKM, 12 (2) :187-193

Prasetyo, B., A. L. Indrayanti' A.R. Hakim dan E.Sulastri. 2017. "Analisis Usaha Tani Padi Sawah di Desa Tumbang Manggu Kecamatan Sanaman Mantikei Kabupaten Katingan Kalimantan Tengah" Agrisilvika 1 (2) : 43-48

Prawesti, N., R. Witjaksono, A.B. Raya. 2010. "Motivasi Anak Petani menjadi Petani" Agro Ekonomika. 17 (1) : 11-18 
Pelealu, A.J.H., W. S. Manoppo dan J. V. Mangindaan. 2018. "Analisis Perhitungan Harga Pokok Produksi Dengan Menggunakan Metode Full Costing Sebagai Dasar Perhitungan Harga Jual (Studi Kasus Pada Kertina's Home Industry)" Jurnal Administrasi Bisnis 6 (2) : 34-40

Sanusi. 2015. "Faktor Penentu Keberhasilan UMKM pada Klaster Bordir dan Konveksi Kudus" Iqtishadia, 8 (1) : 42 - 58

Saraswaty, A.N. 2018. "Kebijakan Publik dan Ritel Modern : Studi Kasus Pelaksanaan Kebijakan Plastik Berbayar" E-Jurnal Ekonomi dan Bisnis Universitas Udayana 7 (1): 113-142

Singarimbun, M. 1989. "Metode dan Proses Penelitian" dalam M. Singarimbun dan Sofian Effendi (Editor). Metode Penelitian Survei. Edisi Revisi. LP3ES. Jakarta.

Suartika, I.M., M. Wijana dan M. Sudrajadinata. 2015. "Kajian Tekno Ekonomi Unit Alat Pencacah Plastik untuk Meningkatkan Nilai Jual Sampah" Dinamika Teknik Mesin,5 (2) : $97-105$

Suci, Y.R. 2017. "Perkembangan UMKM (Usaha Mikro Kecil dan Menengah) di Indonesia" Jurnal Ilmiah Cano Ekonomos 6 (1) : 51 - 58

Suryani, A.S., 2016. "Persepsi Masyarakat dan Analisis Willingness to Pay terhadap Kebijakan Kantong Plastik Berbayar di Jakarta dan Bandung" Kajian 21 (4) : 359 - 376

Widyastuti, I dan D. Mita. 2018. "Akuntansi Perhitungan Harga Pokok Penjualan dengan Metode Pesanan untuk Menentukan Harga Jual" Jurnal Moneter V (1) : 74 - 85 Yuwani, S.H., Irham dan Jamhari. 2014. "Analisis Kelayakan dan Strategi Pengembangan Usaha Budidaya Ikan Air Tawar di Kabupaten Sleman" Agro Ekonomi 25 (2) : 135-143 